\title{
MAJOR SEX DIFFERENCES IN NON-GENOMIC ESTROGEN ACTIONS ON INTRACELLULAR SIGNALING IN MOUSE BRAIN IN VIVO
}

\author{
I. M. ÁBRAHÁM ${ }^{\mathrm{a}, \mathrm{b}}$ AND A. E. HERBISON ${ }^{\mathrm{a}, \mathrm{c} *}$ \\ a Laboratory of Neuroendocrinology, The Babraham Institute, Cambridge \\ CB2 4AT, UK \\ ${ }^{b}$ Neurobiology Research Group, Hungarian Academy of Sciences, Eötvös \\ Loránd University, 1119 Pazmany P. st 1/c, Budapest, Hungary \\ ${ }^{\circ}$ Centre for Neuroendocrinology and Department of Physiology, University of \\ Otago School of Medical Sciences, P.O. Box 913, 9001, Dunedin, \\ New Zealand
}

\begin{abstract}
Rapid effects of estrogen have now been identified throughout the brain but the extent to which these actions may be different in males and females is unknown. Previous work has shown that estrogen rapidly phosphorylates Ser ${ }^{133}$ of cAMP responsive element binding protein (CREB) through a non-genomic mechanism. Using this indicator, we have examined here whether non-genomic estrogen actions occur in a sexually dimorphic manner within the adult brain. Male and female mice were gonadectomized and 3 weeks later treated with 17- $\beta$-estradiol or vehicle for $1 \mathrm{~h}$ prior to perfusion fixation and subsequent CREB and phosphorylated CREB ( $P C R E B$ ) immunostaining of brain sections. The numbers of cells expressing CREB immunoreactivity were not altered by estrogen treatment or different in males and females in any of the brain regions examined. However, estrogen treatment significantly $(P<0.05)$ increased pCREB-immunoreactive cell numbers in the medial preoptic area, ventrolateral division of the ventromedial nucleus, medial septum and CA1 region of the hippocampus of female mice. In contrast, estrogen increased pCREB levels in the medial septum and CA1 but not in the preoptic area or ventromedial nucleus of male mice. To evaluate the extent to which non-genomic estrogen actions may be sexually differentiated within a single neuronal phenotype, dual labeling immunocytochemistry was undertaken to evaluate the gonadotropin-releasing hormone (GnRH) neuronal phenotype. Estrogen significantly $(P<0.05)$ increased the numbers of GnRH neurons expressing pCREB in female but not male mice. Together, these results demonstrate the existence of a marked sex difference in estrogen's nongenomic effects upon brain function in vivo. () 2005 IBRO. Published by Elsevier Ltd. All rights reserved.
\end{abstract}

Key words: CREB, GnRH, preoptic area, hippocampus, estrogen receptor.

${ }^{*}$ Correspondence to: A. E. Herbison, Centre for Neuroendocrinology, Department of Physiology, University of Otago School of Medical Sciences, P.O. Box 913, Dunedin, New Zealand. Tel: +64-3-4797312; fax: +64-3-479-7323

E-mail address: allan.herbison@stonebow.otago.ac.nz (A. E. Herbison). Abbreviations: CREB, cAMP-response element binding protein; ER, estrogen receptor; E2, 17- $\beta$-estradiol; gCTX, retrosplenial granulate cortex; GDX, gonadectomized; GnRH, gonadotropin-releasing hormone; mPOA, medial preoptic area; MS, medial septum; pCREB, phosphorylated CAMP-response element binding protein; VMN, ventromedial nucleus; VMNvl, ventrolateral aspect of the ventromedial nucleus.
A variety of neuronal circuits in the mammalian brain exhibit robust sex differences in structure and function (De Vries, 1990; Simerly, 2002). Hypothalamic regions such as the medial preoptic area (mPOA) and ventromedial nucleus (VMN) contain key sexually differentiated neuronal circuits responsible for controlling reproductive function (Pfaff et al., 1994; Flanagan-Cato, 2000; Simerly, 2002). For example, the $\mathrm{GnRH}$ neurons within the mPOA represent the final output neurons of the network involved in regulating gonadal function (Levine, 2003). Whereas estrogen stimulates a massive increment in $\mathrm{GnRH}$ secretion to induce ovulation in the female mammal, it has no similar effect in males (Herbison, 1998). In addition, clear sex differences have been observed in the effects of estrogen on networks involved in regulating male and female sexual behavior (Pfaff et al., 1994; Flanagan-Cato, 2000). Interestingly, these sexually differentiated actions of estrogen are not confined solely to circuits involved in the modulation of reproductive function but also exist within brain regions such as the hippocampus (Woolley, 2000; Leranth et al., 2003).

The mechanisms underlying the sexually dimorphic effects of estrogen on brain function in the adult are unclear. As one possibility, estrogen may regulate different numbers or populations of cells within a specific brain region of males and females. This is likely to be the case for the sexually dimorphic nucleus of the preoptic area and the spinal nucleus of the bulbocavernosus in the rat (for review see Simerly, 2002) where major sex differences in neuronal number have been identified. Alternatively, estrogen may act on the same neuronal phenotypes but generate a sexually dimorphic response as a result of sexually differentiated intracellular signaling mechanisms.

At present, classical genomic actions are thought to underlie the sexually differentiated effects of estrogen upon the brain. Clear defects in estrogen-dependent male and female reproductive behavior exist in estrogen receptor (ER) knockout mice (Ogawa et al., 1998, 2000) and, where examined, neurochemical sex differences have been found to depend upon ER expression (Simerly et al., 1997). However, there is growing recognition of the importance of rapid mechanisms of estrogen signaling within a diverse array of cell types (Falkenstein et al., 2000; Kelly and Levin, 2001). In particular, it is of note that many of the brain regions displaying sexually dimorphic responses to estrogen also exhibit rapid estrogen effects (Yagi, 1973; Minami et al., 1990; Lagrange et al., 1995; Gu et al., 1999; Rudick and Woolley, 2003) and the possibility that nongenomic mechanisms may also contribute to sexually differentiated responses to estrogen has been suggested 
(Simerly, 2002) but not documented. To define brain regions responding to estrogen in a rapid, non-genomic manner, we and others have used the phosphorylation of CREB by estrogen as a marker of rapid changes in intracellular signaling (Gu et al., 1996; Zhou et al., 1996; Abraham et al., 2003; Abraham et al., 2004). Using this approach, we demonstrate here that major sex differences exist in the non-genomic phosphorylation of cAMP-response element binding protein (CREB) by estrogen within specific brain regions as well as within the gonadotropin-releasing hormone $(\mathrm{GnRH})$ neuronal phenotype itself.

\section{EXPERIMENTAL PROCEDURES}

\section{Animals and experimental design}

Wild-type C57BL6/J $\times$ CBA/Ca mice were bred and housed at the Babraham Institute according to UK Home Office requirements under Project license 80/1475 and experiments approved by The Babraham Institute Animal Welfare and Ethics Committee. All mice were maintained under $12 \mathrm{~h}$ light/dark lighting conditions (lights on 07:00 h) with food and water available ad libitum.

Male and female mice were gonadectomized (GDX) at 40-54 days of age under Avertin anesthesia and used for experiments 3 weeks later. Between 10:00 and 11:00 h, mice were administered $1 \mu \mathrm{g} 17-\beta$-estradiol (E2; Sigma, Poole, UK; in $0.1 \mathrm{ml}$ ethyl oleate vehicle, s.c.) or vehicle alone and killed $1 \mathrm{~h}$ later by an overdose of Avertin ( $0.3 \mathrm{ml} / 20 \mathrm{~g}$ b.w.) followed by perfusion through the heart with ice-cold $4 \%$ paraformaldehyde in phosphate buffer ( $\mathrm{pH} 7.6 ; N=5-6 /$ group). Previous studies in our laboratory have shown that estrogen administered in this manner increases CREB phosphorylation within $15 \mathrm{~min}$ in specific brain regions and that the levels of phosphorylated CREB (pCREB) peak around $1 \mathrm{~h}$ following estrogen treatment (Abraham et al., 2004). Mice from estrogen- and vehicle-treated groups perfused alternately between $10: 00$ and 12:00 $\mathrm{h}$ with all the males were perfused on one day and all the females on another. Brains were removed and post-fixed for $2 \mathrm{~h}$ and placed into $30 \%$ sucrose Tris-buffered saline solution overnight at $4{ }^{\circ} \mathrm{C}$. The following day, a 1:4 series of $30 \mu \mathrm{m}$-thick frozen sections were cut in the coronal plane on a sliding microtome.

\section{Immunocytochemistry and analysis}

Free-floating, peroxidase-based immunocytochemistry was undertaken as reported previously (Abraham et al., 2004). In brief, one set of sections was incubated in each of the two polyclonal rabbit primary antibodies (pCREB, 1:100; CREB, 1:100; Cell Sig- naling Technology, New England Biolabs, Beverly, MA, USA) for $48 \mathrm{~h}$ at $4{ }^{\circ} \mathrm{C}$. This was followed by biotinylated goat anti-rabbit IgGs (1:200; Vector Laboratories, Peterborough, UK for $2 \mathrm{~h}$ ) and the Vector Elite avidin-biotin-HRP complex (1:200 for $2 \mathrm{~h}$ ). Labeling was visualized with nickel-diaminobenzidine tetrahydrochloride. The specificities of the CREB antisera have been reported previously in multiple rodent species including the mouse (McNulty et al., 1998; von Gall et al., 1998). The pCREB antibody detects CREB only when phosphorylated at $\operatorname{Ser}^{133}$ and also phosphorylated forms of the CREB-related proteins ATF-1 and CREM. The omission of primary antibodies in this study resulted in a complete absence of immunoreactivity.

Two further sets of sections underwent dual labeling immunocytochemistry for CREB and GnRH or pCREB and GnRH as described previously (Abraham et al., 2003). Briefly, sections underwent the CREB or pCREB immunostaining as outlined above followed by sequential $\mathrm{GnRH}$ immunocytochemistry using the well characterized LR1 polyclonal rabbit antiserum, peroxidaselabeled goat-anti-rabbit immunoglobulins and the DAB chromogen.

Sections were viewed under a Leica (Nusloch, Germany) DM-RB microscope and a quantitative evaluation of the numbers of pCREB- and CREB-positive nuclei undertaken by a "blinded" investigator using a computer based imaging system (AIS 6.0, Rev 1.3; Imaging Research Inc., Ontario, Canada) with the images digitized using a Sony CCD (DXC 950P) camera. Four brain regions (ventrolateral aspect of the VMN, VMNvl; medial septum, MS, mPOA, CA1 hippocampus) were selected for analysis on the basis of prior work showing that estrogen induced CREB phosphorylation in these areas through a rapid, non-genomic mechanism (Abraham et al., 2003, 2004). A fifth area, the retrosplenial granulate cortex (gCTX) was also examined as we had shown previously that it did not respond to estrogen in female mice (Abraham et al., 2004). The GnRH neurons were selected as a specific neuronal phenotype to investigate as estrogen is known to rapidly phosphorylate CREB in these cells in a direct manner (Abraham et al., 2003), and because they represent a neuronal phenotype for which estrogen feedback actions are physiologically relevant and sexually differentiated (Herbison, 1998).

For each brain region, two sections were selected at the appropriate level (see below) in each mouse ( $n=5-6 /$ group) and bilateral cell counts undertaken by counting all CREB or pCREB immunoreactive cell nuclei within a specified rectangle (Fig. 1) as defined; $\mathrm{VMNvl}$, rectangle size $0.04 \mathrm{~mm}^{2}$, anterior-posterior level=plate $42 / 43$ of the Franklin and Paxinos (1997) atlas; MS, $0.48 \mathrm{~mm}^{2}$, plate 25/26; gCTX, $0.27 \mathrm{~mm}^{2}$, plate 49/50; CA1, $1.5 \mathrm{~mm}^{2}$, plate 49/50; mPOA, $0.43 \mathrm{~mm}^{2}$, plate $30 / 31$ (Fig. 2A). For $\mathrm{GnRH}$ neurons, two sections at the level of the rostral preoptic area (plates 25 and 26 ) were selected from each animal and the number of single $(\mathrm{GnRH})$ and dual-labeled neurons $(\mathrm{GnRH}+$
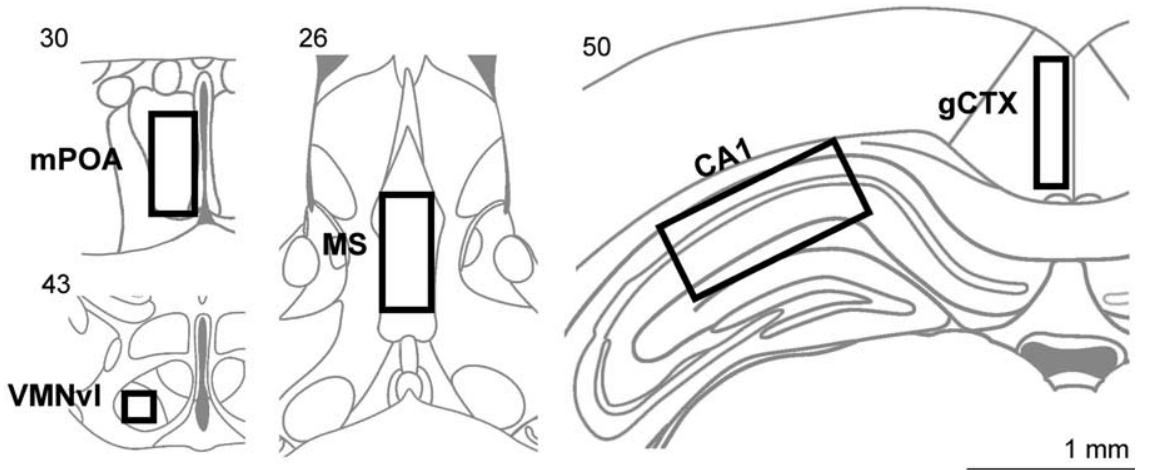

Fig. 1. Brain regions analyzed for sex differences in rapid estrogen actions upon CREB phosphorylation. The rectangles show the precise areas analyzed for CREB- and PCREB-immunoreactive cell numbers in the MPOA, VMNvl, MS, CA1 hippocampus and gCTX. Coronal brain sections adapted from Franklin and Paxinos (1997) with the plate number from that atlas given at the top left of each schematic. 

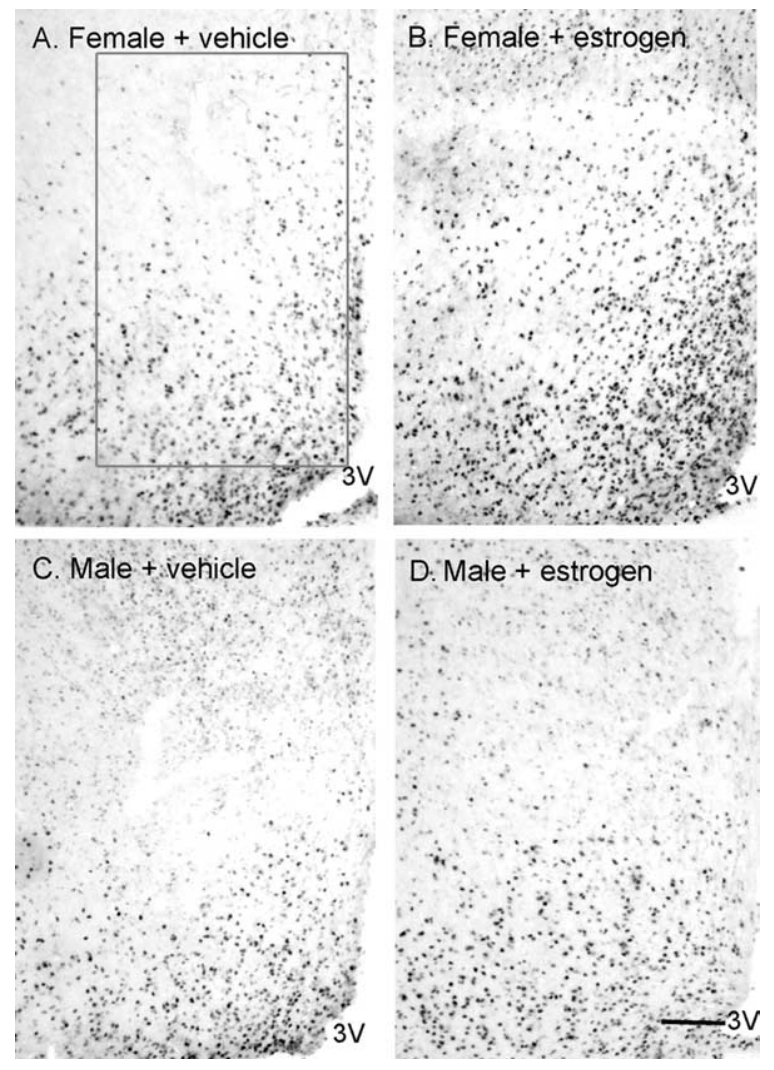

Fig. 2. Sex differences in E2-induced CREB phosphorylation in the mPOA. Photomicrographs of $p C R E B$ immunoreactivity in the mPOA of GDX female $(A, B)$ and male $(C, D)$ mice treated with vehicle $(A, C)$ or E2 $(B, D)$. Whereas estrogen increases the numbers of pCREBimmunoreactive cells in females, it has no effect in male mice. In all plates the third ventricle $(3 \mathrm{~V})$ is immediately to the right. Scale bar $=100 \mu \mathrm{m}$ in $D$ and is the same for all plates. The rectangle in $A$ indicates the area analyzed.

pCREB or GnRH+CREB) determined by an investigator blind to the experimental groupings. We only considered a $\mathrm{GnRH}$ neuron to be expressing CREB/pCREB if the nucleus displayed a uniform, dense black immunoreactive product. Although underrepresenting absolute CREB/pCREB expression in the $\mathrm{GnRH}$ neurons, this ensured consistency in our counting analysis.

\section{Statistical analysis}

Mean (+SEM) values were obtained from averaging the two cell counts from each area from each mouse within the experimental groups $(n=5-6)$. The CREB and pCREB expression in GnRH neurons was calculated as a percentage of total $\mathrm{GnRH}$ neuron number and the brain region data are depicted as total numbers of immunoreactive cell counts. Statistical analysis was undertaken by two-way ANOVA with Tukey post hoc test. All statistical analyses were performed using Statistica for Windows 5.1 software (StatSoft)

\section{RESULTS}

\section{CREB and $P C R E B$ in specific brain regions}

Immunolabeling for CREB and $\mathrm{PCREB}$ revealed an exclusively nuclear pattern of staining (Fig. 2) that existed in an heterogeneous manner throughout the coronal brain sec- tions. No sex differences were detected in CREB or pCREB immunoreactivity in vehicle-treated male and female GDX mice (Figs. 2 and 3). Also, in both sexes, estrogen treatment was found to have no effect upon the numbers of CREB-immunoreactive cells detected in any of the areas examined (Fig. 3A). In terms of pCREB, however, estrogen treatment in GDX female mice induced a significant $(P<0.05)$ increase in the number of pCREBimmunoreactive cells detected in the $\mathrm{MPOA}(78 \%$; Fig. $1 \mathrm{~A}, \mathrm{~B})$, MS (76\%), VMNvl (38\%) and CA1 hippocampus (151\%; Fig. 3B) without altering cell numbers in the gCTX (not shown). In contrast, estrogen treatment of GDX males increased the numbers of pCREB-immunoreactive cells in the MS $(71 \%)$ and CA1 (148\%) but had no effect upon pCREB in the MPOA (Fig. 2C, D) or VMNvl (Fig. 3B), or in the gCTX (not shown). These data indicate a marked, region-dependent sex difference in the ability of estrogen to elicit CREB phosphorylation in the mouse brain.

\section{CREB and $P C R E B$ in GnRH neurons}

To evaluate whether the sex differences in estrogen phosphorylation of CREB observed in heterogeneous brain regions might also hold true for a specific neuronal phenotype, experiments were undertaken to analyze the $\mathrm{GnRH}$ neurons. The distribution of $\mathrm{GnRH}$ neurons was the same as that reported previously in the mouse (Jennes and Stumpf, 1986; Skynner et al., 1999). The number of $\mathrm{GnRH}$ neurons detected within the rostral preoptic area was not influenced by estrogen treatment or different in males and females (male-vehicle, $17 \pm 1 \mathrm{GnRH}$ neurons/ section; male-estrogen, $16 \pm 1$; female-vehicle, $15 \pm 2$; female-estrogen, $17 \pm 2$ ). Dual-labeled cells were readily identified as cells exhibiting a brown cytoplasmic stain and a black nucleus (Fig. 4A). Approximately $25-30 \%$ of $\mathrm{GnRH}$ neurons were detected to express CREB and this was not influenced by estrogen or sexually differentiated (Fig. 4B). In contrast, the percentage of $\mathrm{GnRH}$ neurons expressing pCREB in GnRH neurons was markedly different $(P<0.05)$ in vehicle-treated males $(22 \%)$ and females (4\%; Fig. $4 C)$. Furthermore, estrogen induced a significant $(P<0.05)$ increase in the numbers of $\mathrm{GnRH}$ neurons expressing pCREB in females but had no effect in male mice (Fig. 4C). These observations suggest that a marked sex difference exists in both the basal levels of CREB phosphorylation in the GnRH neurons of GDX mice as well as in the ability of estrogen to elicit CREB phosphorylation in these cells.

\section{DISCUSSION}

These studies indicate that major sex differences exist in the rapid, non-genomic influences of estrogen upon brain function. We have shown previously that estrogen increases CREB phosphorylation within $15 \mathrm{~min}$ in the mPOA, VMNvl, MS and CA1 hippocampus and GnRH neuronal phenotype of GDX female mice in vivo, and that this response is maximal at 60 min (Abraham et al., 2003, 2004). Using the same experimental paradigm, we now demonstrate that estrogen has different effects upon PCREB phosphorylation in the brain of GDX male mice. 


\section{A. CREB $\square$ vehicle $\square$ estrogen B. pCREB $\square$ vehicle $\square$ estrogen}
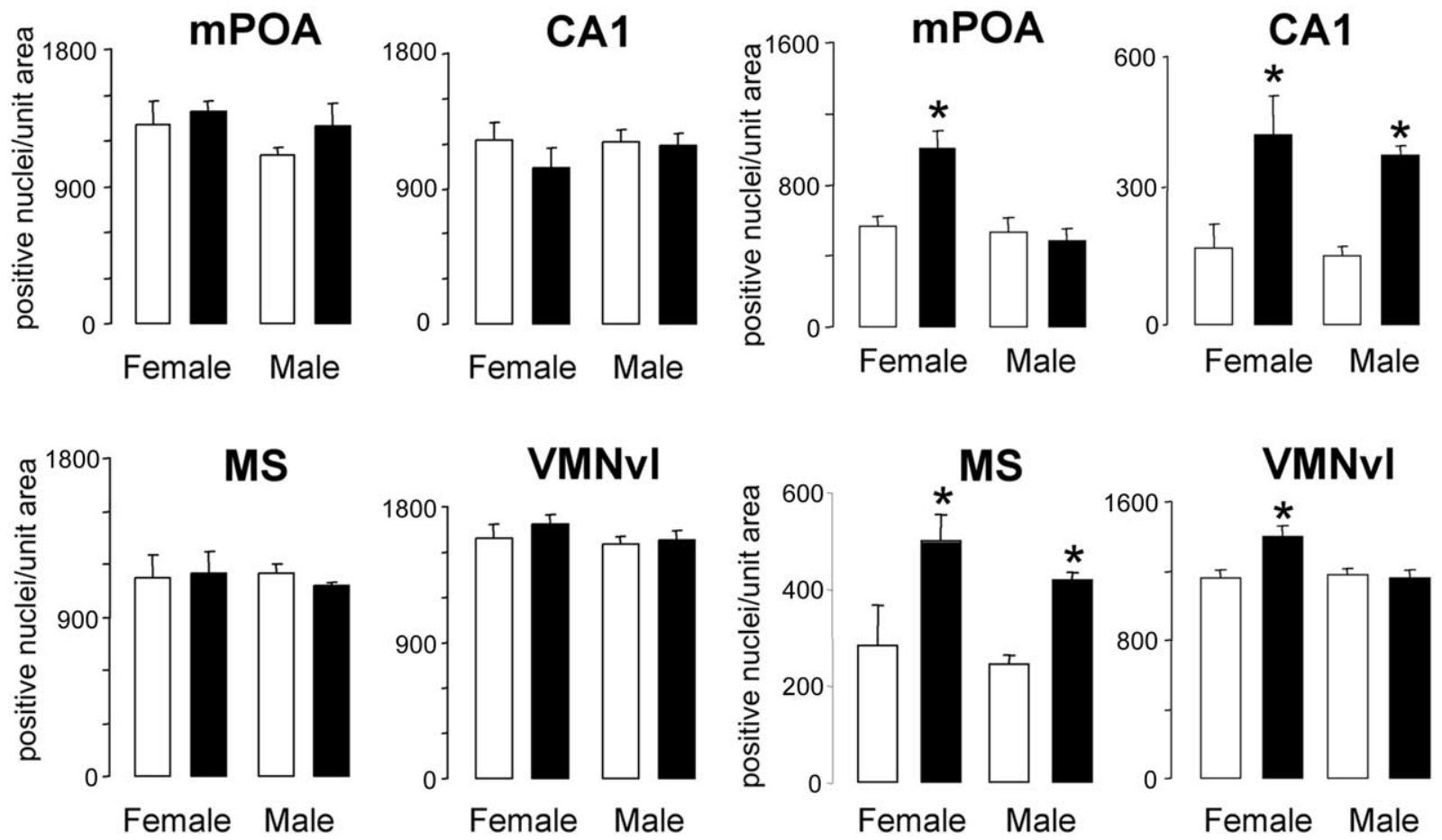

Fig. 3. Region-specific sex differences in CREB phosphorylation by estrogen. Histograms showing mean (+S.E.M.) number of CREB- (A) and pCREB- (B) immunoreactive cells detected per unit area in the mPOA, CA1 hippocampus, MS and VMNvl of GDX male and female mice given vehicle or E2 (estrogen). ${ }^{*} P<0.05$ compared with vehicle-treated mice. $N=5-6 /$ group.

Whereas, estrogen-induced CREB phosphorylation was observed in the MS and CA1 of males, no effects were detected in the mPOA, VMNvl or GnRH neuronal phenotype. As no sex differences exist in CREB expression in the $\mathrm{GnRH}$ neurons or these brain areas, the sexually differentiated responses must result from differences in the phosphorylation of $\mathrm{Ser}^{133}$ on CREB. Together, these results provide initial evidence that non-genomic mechanisms of estrogen action may contribute to the sexually dimorphic influence of estrogen on adult brain function. At least one cellular locus of this differential estrogen action is the $\mathrm{GnRH}$ neurons.

\section{Sex differences in rapid estrogen actions upon reproductive behavioral circuits}

Neural circuits within the MPOA and VMN are critical sites of estrogen action in the regulation of sexually differentiated sexual behavior (Pfaff et al., 1994; Flanagan-Cato, 2000). The mPOA, in particular, exhibits a wide variety of neurochemical and structural sexual dimorphisms that are thought to underlie elements of male reproductive behavior (reviewed in De Vries, 1990; Simerly, 2002). As such, sex differences in the effects of estrogen within this area may arise from estrogen actions upon different numbers or types of ER-

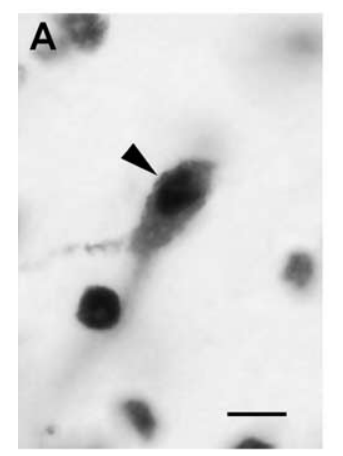

B. GnRH-CREB

\section{GnRH-pCREB}

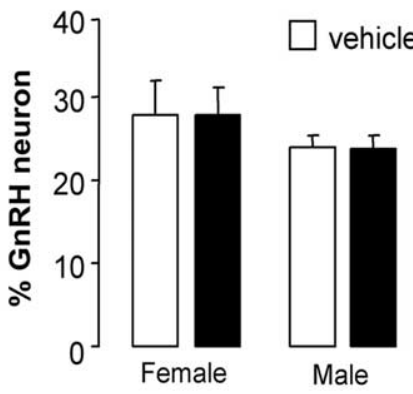

estrogen

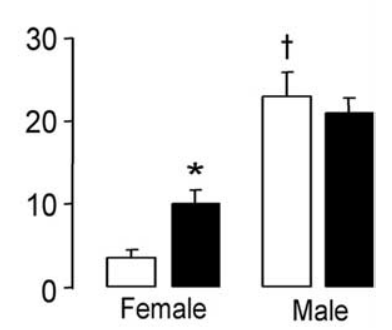

Fig. 4. Sex differences in CREB phosphorylation by estrogen in the GnRH neuronal phenotype. Photomicrograph (A) shows a double-labeled (arrowhead) GnRH neuron (gray cytoplasm) with pCREB-positive nucleus (black). Histograms showing mean (+S.E.M.) number of dual-labeled GnRH-CREB- (B) and GnRH-pCREB- (C) immunoreactive neurons detected in the mPOA of GDX male and female mice given vehicle or E2 (estrogen). ${ }^{*} P<0.05$ compared with vehicle-treated mice. ${ }^{\dagger} P<0.05$ compared with vehicle-treated female. $N=5-6 / g r o u p . ~ S c a l e ~ b a r=10 \mu m$ in A. 
expressing cells in the two sexes. For example, twice as many neurotensin neurons in the mPOA express ER $\alpha$ in female rats compared with males (Herbison and Theodosis, 1992). Although the receptors underlying non-genomic estrogen effects remain unclear (Toran-Allerand, 2004), we have recently shown that the rapid effects of estrogen upon CREB phosphorylation in mouse brain require the presence of the classical ERs (Abraham et al., 2004). Thus, sex differences in estrogen actions within the MPOA may arise through classical genomic as well as rapid mechanisms that, nevertheless, both depend upon sexually differentiated ER expression. The identity and functions of the mPOA cells in the female identified here to respond to estrogen in a rapid manner are yet to be established.

In contrast to the mPOA, relatively few neurochemical and structural sex differences have been identified within the VMNvl (Sakuma, 1984; Matsumoto and Arai, 1986; Grattan and Selmanoff, 1997), the sub-region of the VMN expressing ERs and implicated in female sexual behavior. The estrogen-induced activation of CREB phosphorylation in the $\mathrm{VMNvl}$ is dependent upon $\mathrm{ER} \alpha$ (Abraham et al., 2004) but similar levels of ER $\alpha$ appear to exist in this region in male and female rats (Herbison, 1994). Hence, the sexually dimorphic response of this brain area may depend upon sex differences downstream of the ER itself. As the ER-expressing cells of the VMNvl are considered a critical target for estrogen in enabling lordosis in female rodents (Pfaff et al., 1994), the present results raise the possibility that non-genomic actions of estrogen may contribute to the physiological regulation of female reproductive behavior. What role enhanced pCREB levels may have within VMNvl neurons in the female is not known. However, it is interesting to note that estrogen's potent effects upon dendritic spine morphology require the phosphorylation of CREB (Murphy and Segal, 1997) and there is good evidence for estrogen-dependent re-modeling of dendritic structure in the VMNvl (Frankfurt et al., 1990; Woolley, 2000).

A prior study reported that sex differences existed in the numbers of cells expressing pCREB within the $\mathrm{MPOA}$, VMNvl and CA1 of newborn rats (Auger et al., 2001). In all three brain regions, male rats were found to have more pCREB than females and, interestingly, it was suggested that this might relate to enhanced endogenous estrogen exposure in newborn males (Auger et al., 2001).

\section{Absence of sex differences in rapid estrogen actions in the CA1 hippocampus}

We show here that the rapid actions of estrogen upon CREB phosphorylation are equivalent in the CA1 hippocampus and MS of male and female mice. Estrogen has been found previously to exert rapid effects upon the electrical responses (Gu et al., 1999), immediate early gene expression (Rudick and Woolley, 2003) and second messenger phosphorylation patterns of CA1 neurons (Kuroki et al., 2001; Abraham et al., 2003; Lee et al., 2004). A prior electrophysiological study had investigated whether sex differences may exist in rapid estrogen actions within the hippocampus and, as found here for PCREB, no sexual dimorphism was evident (Fugger et al., 2001). This indicates that the established sex difference in the ability of estrogen to modulate dendritic spine density in the CA1 (Woolley and McEwen, 1992; Leranth et al., 2003), is unlikely to depend simply on sex differences in CREB phosphorylation. The intracellular pathways mediating the effects of estrogen upon CREB phosphorylation in the hippocampus are currently under examination. Studies in vitro have shown that both the mitogen-activated protein kinase and calcium-calmodulin kinase pathways are likely to be upstream signaling pathways (Lee et al., 2004). However, it is curious that the phosphorylation of CREB in the CA1 hippocampus in vivo is critically dependent upon ER $\beta$ (Abraham et al., 2003). There is relatively little ER $\beta$ expressed in the CA1 hippocampus of the mouse (Mitra et al., 2003) suggesting that rapid CREB phosphorylation in CA1 neurons may not occur directly and depend, instead, upon estrogen-sensitive neuronal inputs to this area (Leranth et al., 2000).

\section{Sex differences in rapid estrogen actions upon GnRH neurons}

The GnRH neurons exhibit major sex differences in functioning that are critical to the physiological regulation of fertility in mammals. In response to elevated circulating estrogen levels, the $\mathrm{GnRH}$ neurons in females exhibit a burst of activity resulting in the mid-cycle $\mathrm{GnRH}$ surge that initiates ovulation (Herbison, 1998). In males, estrogen is only found to suppress $\mathrm{GnRH}$ secretion and the nature of this fundamental sex difference is not understood. This correlates well with the observed expression of c-Fos in $\mathrm{GnRH}$ neurons of females but not males treated with appropriate steroids (Hoffman et al., 1993). With respect to the presence of ERs, GnRH neurons are only known to express ER $\beta$ (Herbison and Pape, 2001) and no sex differences in $\mathrm{ER} \beta$ expression by $\mathrm{GnRH}$ neurons have been observed in the rat (Hrabovszky et al., 2001). Hence, it seems most likely that sex differences originate from either sexually dimorphic, estrogen-sensitive synaptic inputs to the GnRH neurons (Chen et al., 1990) or from sex differences in intracellular signaling events downstream from ER $\beta$.

We report here two clear sex differences related to CREB phosphorylation within the GnRH neuronal phenotype. In the first instance, we have observed that the levels of pCREB in GnRH neurons of vehicle-treated GDX adult mice are very different with males having higher expression than females. This suggests that sex differences exist in the intracellular phosphorylation machinery of male and female GnRH neurons in GDX mice. Although sex differences are apparent in the rate at which pulsatile LH secretion achieves maximal levels in the first few days following gonadectomy (Gay and Midgley, 1969; Yamamoto et al., 1970), it has been thought that the secretory and biosynthetic behavior of "free-running" GnRH neurons in 2-3 week GDX male and female animals is similar. Certainly, single point plasma luteinizing hormone levels in 2 week GDX mice are the same in males and females (Thanky et al., 2003). However, the present results clearly suggest that CRE- 
dependent gene transcription within $\mathrm{GnRH}$ neurons is unlikely to be the same in GDX male and female mice.

The second sexually differentiated feature of CREB phosphorylation in $\mathrm{GnRH}$ neurons relates to the effects of estrogen on its phosphorylation status. Whereas estrogen increased CREB phosphorylation in $\mathrm{GnRH}$ neurons in GDX females, it was found to have no effect in males. On one hand this might be explained by the already high numbers of $\mathrm{GnRH}$ neurons expressing pCREB in GDX males that may have precluded us from observing a further increment after estrogen treatment. It is possible that only approximately $25 \%$ of the heterogeneous $\mathrm{GnRH}$ population will ever respond to estrogen in this manner and that they also happen to be the cells that express high levels of CREB. On the other hand, the sex difference in rapid estrogen action may be explained by the absence of estrogendependent inputs or pathways phosphorylating CREB in the male $\mathrm{GnRH}$ neuron. What genes estrogen may be regulating through CREB response elements in females is not known at this stage. As indicated above, the concept of sex differences in the behavior of the $\mathrm{GnRH}$ neurons outside that of the preovulatory $\mathrm{GnRH}$ surge has not been explored widely (Herbison, 1998). Together with recent data demonstrating sex differences in $\mathrm{GnRH}$ gene transcription mechanisms in the context of estrogen negative feedback (Thanky et al., 2003), these results suggest that many aspects of $\mathrm{GnRH}$ neuron physiology may be sexually differentiated.

In conclusion, the present study demonstrates that major sex differences exist in the rapid effects of estrogen upon intracellular signaling within brain regions implicated in reproductive control. The fact that a sex differences exists implies a degree of selectivity in rapid estrogen effects upon neurons and supports the possibility that rapid estrogen signaling may be physiological relevant. As the rapid phosphorylation of CREB by estrogen requires the presence of the classical ER (Abraham et al., 2004), these findings indicate that nongenomic sex differences may result from sexually differentiated ER expression and/or sex differences in intracellular signaling cascades linking the ER to CREB phosphorylation. Together these findings suggest that non-genomic actions of estrogen may contribute to the sexually dimorphic activation of neuronal circuits by this steroid in the adult brain.

Acknowledgments-We thank Dr. R. Benoit for the LR1 antiserum and Sandra Dye and members of the Babraham Institute SABU for assistance. Drs. Rebecca Campbell and Christine Jasoni are thanked for comments on an earlier version of the manuscript. This research was supported by the BBSRC, Wellcome Trust, Marie Curie Fellowship and Reintegration Grant of the European Community Human Potential Programme (HPMF-CT-200000512, 511056), National Science Research crant OTKA 030681, 047217 and a Bolyai János Research Fellowship.

\section{REFERENCES}

Abraham IM, Han K, Todman MG, Korach KS, Herbison AE (2003) Estrogen receptor $\beta$ mediates rapid estrogen actions on gonadotropin-releasing hormone neurons in vivo. J Neurosci 23:5771-5777.
Abraham IM, Todman MG, Korach KS, Herbison AE (2004) Critical in vivo roles for classical estrogen receptors in rapid estrogen actions on intracellular signaling in mouse brain. Endocrinology 145:3055-3061.

Auger AP, Hexter DP, McCarthy MM (2001) Sex difference in the phosphorylation of CAMP response element binding protein (CREB) in neonatal rat brain. Brain Res 890:110-117.

Chen W-P, Witkin JW, Silverman A-J (1990) Sexual dimorphism in the synaptic input to gonadotropin releasing hormone neurons. Endocrinology 126:695-702.

De Vries GJ (1990) Sex differences in neurotransmitter systems. $\mathrm{J}$ Neuroendocrinol 2:1-13.

Falkenstein E, Tillmann H-C, Christ M, Feuring M, Wehling M (2000) Multiple actions of steroid hormones: a focus on rapid, nongenomic effects. Pharmacol Rev 52:513-555.

Flanagan-Cato LM (2000) Estrogen-induced remodeling of hypothalamic neural circuitry. Front Neuroendocrinol 21:309-329.

Frankfurt M, Gould E, Woolley CS, McEwen BS (1990) Gonadal steroids modify dendritic spine density in ventromedial hypothalamic neurons: a Golgi study in the adult rat. Neuroendocrinology 51:530-535.

Franklin KBJ, Paxinos G (1997) The mouse brain in stereotaxic coordinates. San Diego: Academic Press.

Fugger HN, Kumar A, Lubahn DB, Korach KS, Foster TC (2001) Examination of estradiol effects on the rapid estradiol mediated increase in hippocampal synaptic transmission in estrogen receptor alpha knockout mice. Neurosci Lett 309:207-209.

Gay VL, Midgley R (1969) Response of the adult rat to orchidetomy and ovariectomy as determined by LH radioimmunoassay. Endocrinology 84:1359-1364.

Grattan DR, Selmanoff M (1997) Sex differences in the activity of gamma-aminobutyric acidergic neurons in the rat hypothalamus. Brain Res 775:244-249.

Gu G, Rojo AA, Zee MC, Yu J, Simerly RB (1996) Hormonal regulation of CREB phosphorylation in the anteroventral periventricular nucleus. J Neurosci 16:3035-3044.

Gu Q, Korach KS, Moss RL (1999) Rapid action of 17 beta-estradiol on kainate-induced currents in hippocampal neurons lacking intracellular estrogen receptors. Endocrinology 140:660-666.

Herbison AE (1994) Somatostatin-immunoreactive neurones in the hypothalamic ventromedial nucleus possess oestrogen receptors in the male and female rat. J Neuroendocrinol 6:323-328.

Herbison AE (1998) Multimodal influence of estrogen upon gonadotropinreleasing hormone neurons. Endocr Rev 19:302-330.

Herbison AE, Pape JR (2001) New evidence for estrogen receptors in gonadotropin-releasing hormone neurons. Front Neuroendocrinol 22:292-308.

Herbison AE, Theodosis DT (1992) Localisation of oestrogen receptors in preoptic neurons containing neurotensin but not tyrosine hydroxylase, cholecystokinin or luteinizing hormone-releasing hormone in the male and female rat. Neuroscience 50:283-298.

Hoffman GE, Smith MS, Verbalis JG (1993) c-Fos and related immediate early gene products as markers of activity in neuroendocrine systems. Front Neuroendocrinol 14:173-213.

Hrabovszky E, Steinhauser A, Barabas K, Shughrue PJ, Petersen SL, Merchenthaler I, Liposits Z (2001) Estrogen receptor- $\beta$ immunoreactivity in luteinizing hormone-releasing hormone neurons of the rat brain. Endocrinology 142:3261-3264.

Jennes L, Stumpf WE (1986) Gonadotropin-releasing hormone immunoreactive neurons with access to fenestrated capillaries in mouse brain. Neuroscience 18:403-416.

Kelly MJ, Levin ER (2001) Rapid actions of plasma membrane estrogen receptors. Trends Endocrinol Metab 12:152-156.

Kuroki Y, Fukushima K, Kanda Y, Mizuno K, Watanabe Y (2001) Neuroprotection by estrogen via extracellular signal-regulated kinase against quinolinic acid-induced cell death in the rat hippocampus. Eur J Neurosci 13:472-476. 
Lagrange AH, Rønnekleiv OK, Kelly MJ (1995) Estradiol-17 $\beta$ and $\mu$-opioid peptides rapidly hyperpolarize $\mathrm{GnRH}$ neurons: a cellular mechanism of negative feedback. Endocrinology 136:2341-2344.

Lee SJ, Campomanes CR, Sikat PT, Greenfield AT, Allen PB, McEwen BS (2004) Estrogen induces phosphorylation of cyclic AMP response element binding ( $\mathrm{PCREB}$ ) in primary hippocampal cells in a time-dependent manner. Neuroscience 124:549-560.

Leranth C, Petnehazy O, MacLusky NJ (2003) Gonadal hormones affect spine synaptic density in the CA1 hippocampal subfield of male rats. J Neurosci 23:1588-1592.

Leranth C, Shanabrough M, Horvath TL (2000) Hormonal regulation of hippocampal spine synapse density involves subcortical mediation. Neuroscience 101:349-356.

Levine JE (2003) Gonadotropin-releasing hormone (GnRH). In: Encyclopedia of hormones, Vol. 2 (Henry H, Norman A, eds), pp 157165. San Diego: Academic Press.

Matsumoto A, Arai Y (1986) Male-female difference in synaptic organization of the ventromedial nucleus of the hypothalamus in the rat. Neuroendocrinology 42:232-236.

McNulty S, Schurov IL, Sloper PJ, Hastings MH (1998) Stimuli which entrain the circadian clock of the neonatal Syrian hamster in vivo regulate the phosphorylation of the transcription factor CREB in the suprachiasmatic nucleus in vitro. Eur J Neurosci 10:1063-1072.

Minami T, Oomura Y, Nabekura J, Fukuda A (1990) 17 beta-Estradiol depolarization of hypothalamic neurons is mediated by cyclic AMP. Brain Res 519:301-307.

Mitra SW, Hoskin E, Yudkovitz J, Pear L, Wilkinson HA, Hayashi S, Pfaff DW, Ogawa S, Rohrer SP, Schaeffer JM, McEwen BS, Alves SE (2003) Immunolocalization of estrogen receptor beta in the mouse brain: comparison with estrogen receptor alpha. Endocrinology 144:2055-2067.

Murphy DD, Segal M (1997) Morphological plasticity of dendritic spines in central neurons is mediated by activation of cAMP response element binding protein. Proc Natl Acad Sci USA 94: 1482-1487.

Ogawa S, Chester AE, Hewitt SC, Walker VR, Gustafsson JA, Smithies O, Korach KS, Pfaff DW (2000) Abolition of male sexual behaviors in mice lacking estrogen receptors alpha and beta (alpha beta ERKO). Proc Natl Acad Sci USA 97: 14737-14741.

Ogawa S, Eng V, Taylor J, Lubahn DB, Korach KS, Pfaff DW (1998) Roles of estrogen receptor-alpha gene expression in reproductionrelated behaviors in female mice. Endocrinology 139:5070-5081.

Pfaff DW, Schwartz-Giblin S, McCarthy MM, Kow L-M (1994) Cellular and molecular mechanisms of female reproductive behaviors. In:
The physiology of reproduction (Knobil E, Neill JD, eds), pp 107-220. New York: Raven Press Ltd.

Rudick CN, Woolley CS (2003) Selective estrogen receptor modulators regulate phasic activation of hippocampal CA1 pyramidal cells by estrogen. Endocrinology 144:179-187.

Sakuma Y (1984) Influences of neonatal gonadectomy or androgen exposure on the sexual differentiation of the rat ventromedial hypothalamus. J Physiol 349:273-286.

Simerly RB (2002) Wired for reproduction: organization and development of sexually dimorphic circuits in the mammalian forebrain. Annu Rev Neurosci 25:507-536.

Simerly RB, Zee MC, Pendleton JW, Lubahn DB, Korach KS (1997) Estrogen receptor-dependent sexual differentiation of dopaminergic neurons in the preoptic region of the mouse. Proc Natl Acad Sci USA 94:14077-14082.

Skynner MJ, Slater R, Sim JA, Allen ND, Herbison AE (1999) Promoter transgenics reveal multiple gonadotropin-releasing hormone-1expressing cell populations of different embryological origin in mouse brain. J Neurosci 19:5955-5966.

Thanky NR, Slater R, Herbison AE (2003) Sex differences in estrogendependent transcription of gonadotropin-releasing hormone $(\mathrm{GnRH})$ gene revealed in $\mathrm{GnRH}$ transgenic mice. Endocrinology 144: 3351-3358.

Toran-Allerand CD (2004) Minireview: a plethora of estrogen receptors in the brain: where will it end? Endocrinology 145:1069-1074

von Gall C, Duffield GE, Hastings MH, Kopp MD, Dehghani F, Korf HW, Stehle JH (1998) CREB in the mouse SCN: a molecular interface coding the phase-adjusting stimuli light, glutamate, PACAP, and melatonin for clockwork access. J Neurosci 18:10389-10397.

Woolley CS (2000) Effects of oestradiol on hippocampal circuitry. Novartis Found Symp 230:173-180.

Woolley CS, McEwen BS (1992) Estradiol mediates fluctuation in hippocampal synapse density during the estrous cycle in the adult rat. J Neurosci 12:2549-2554.

Yagi K (1973) Changes in firing rates of single preoptic and hypothalamic units following an intravenous administration of estrogen in the castrated female rat. Brain Res 53:343-352.

Yamamoto M, Diebel ND, Bogdanove EM (1970) Analysis of initial and delayed effects of orchidectomy and ovariectomy on pituitary and serum LH levels in adult and immature rats. Endocrinology 86: 1102-1111.

Zhou Y, Watters JJ, Dorsa DM (1996) Estrogen rapidly induces the phosphorylation of the cAMP response element binding protein in rat brain. Endocrinology 137:2163-2166. 